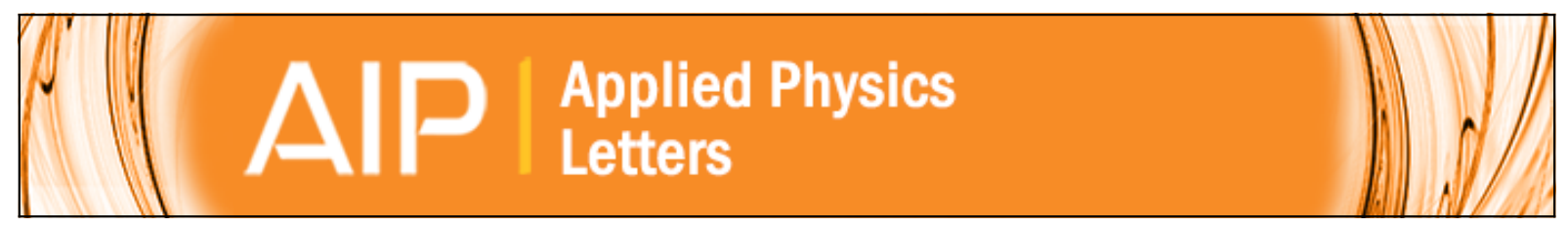

\title{
Aluminum mobility and interfacial segregation in fully silicided gate contacts
}

R. P. Pezzi, M. Copel, C. Cabral Jr., and I. J. R. Baumvol

Citation: Applied Physics Letters 87, 162902 (2005); doi: 10.1063/1.2103392

View online: http://dx.doi.org/10.1063/1.2103392

View Table of Contents: http://scitation.aip.org/content/aip/journal/apl/87/16?ver=pdfcov

Published by the AIP Publishing

\section{Articles you may be interested in}

p+-doping analysis of laser fired contacts for silicon solar cells by Kelvin probe force microscopy

J. Appl. Phys. 119, 105707 (2016); 10.1063/1.4943064

Tuning the Schottky barrier height of nickel silicide on $\mathrm{p}$-silicon by aluminum segregation

Appl. Phys. Lett. 92, 222114 (2008); 10.1063/1.2940596

Interfacial segregation of dopants in fully silicided metal-oxide-semiconductor gates

Appl. Phys. Lett. 86, 251904 (2005); 10.1063/1.1951046

Diffusion and segregation of shallow As and $\mathrm{Sb}$ junctions in silicon

J. Vac. Sci. Technol. B 22, 455 (2004); 10.1116/1.1632919

Interfacial and bulk properties of zirconium dioxide as a gate dielectric in metal-insulator-semiconductor structures and current transport mechanisms

J. Appl. Phys. 93, 4788 (2003); 10.1063/1.1561995

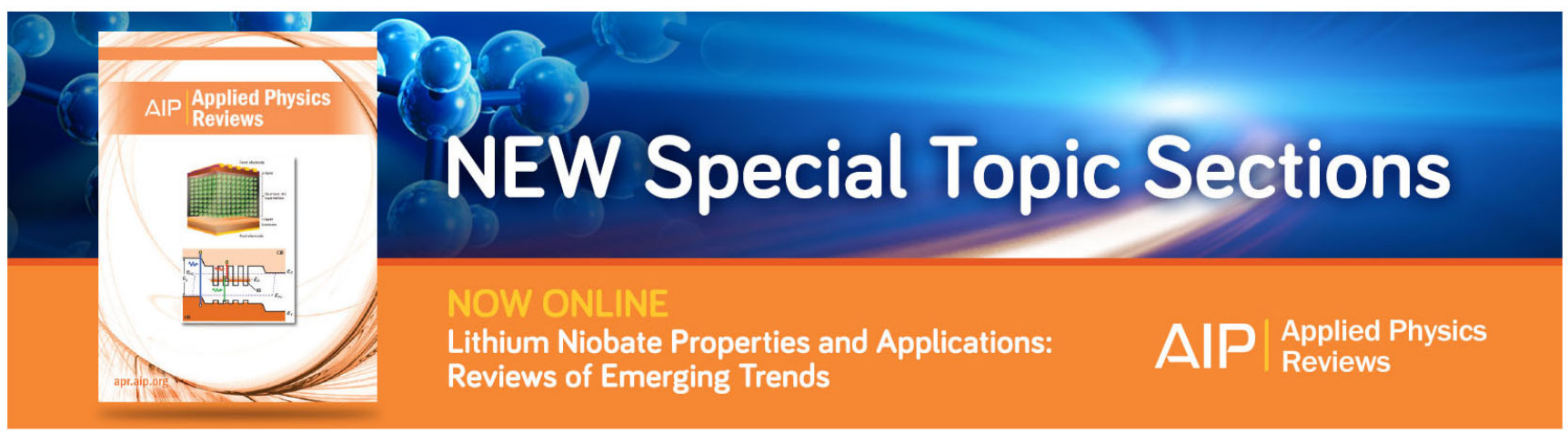




\title{
Aluminum mobility and interfacial segregation in fully silicided gate contacts
}

\author{
R. P. Pezzia) \\ Instituto de Física, UFRGS, Av. Bento Gonçalves 9500, Porto Alegre, RS, Brazil 91509-900 \\ M. Copel and C. Cabral, Jr. \\ IBM Research Division, T. J. Watson Research Center, P.O. Box 218, Yorktown Heights, New York 10598 \\ I. J. R. Baumvol \\ Centro de Ciências Exatas e Tecnológicas, UCS, Caxias do Sul, RS, Brazil 95070-560 \\ and Instituto de Física, UFRGS, Av. Bento Gonçalves 9500, Porto Alagre, RS, Brazil 95070-560
}

(Received 2 May 2005; accepted 23 August 2005; published online 12 October 2005)

\begin{abstract}
The mobility of aluminum implanted as a dopant of fully silicided nickel for advanced metal gates has been investigated following rapid thermal annealing at temperatures ranging from 160 to $700{ }^{\circ} \mathrm{C}$. Resonant nuclear reaction profiling using the ${ }^{27} \mathrm{Al}(p, \gamma){ }^{28} \mathrm{Si}$ reaction was used for aluminum quantification and depth profiling. The results indicate that there is no significant aluminum loss in the whole annealing temperature interval. Furthermore, aluminum is seen to segregate near the interface with silicon oxide during metal silicidation, forming a stable layer of aluminum oxide. (C) 2005 American Institute of Physics. [DOI: 10.1063/1.2103392]
\end{abstract}

Intensive efforts are being directed to the development of alternative materials to continue complementary metaloxide-semiconductor (CMOS) devices downscaling. Advances are expected from the use of alternative gate dielectric and contact materials, namely high- $\kappa$ dielectrics and metal gates. The use of fully silicided (FUSI) gated CMOS stands as a convenient choice since the starting structure is a standard polysilicon gated device, which is then reacted with an overlying metal layer, creating the metal gate. On the other hand, each particular choice of silicide presents a single work function, making it difficult to adjust the threshold voltage for both $n$-type field-effect transistors ( $n$ FETs) and $p$-type field-effect transistors ( $p$ FETs). This last difficulty can be overcome, ${ }^{1-3}$ since within certain limits the threshold voltage can be finely adjusted by adding dopants to the polysilicon layer prior to silicidation.

Recently, $\mathrm{Sb}$ and $\mathrm{Al}$ dopants bonding and $\mathrm{Sb}$ mobility and segregation near the $\mathrm{NiSi} / \mathrm{SiO}_{2}$ interface after metal silicidation was reported, as studied by x-ray photoelectron spectroscopy (XPS) and medium energy ion scattering (MEIS). ${ }^{4}$ In order to take advantage of high resolution depth profiling and other surface science techniques, inverted device structures were probed, such that the interface between silicon oxide and $\mathrm{NiSi}$ can then be found close to the surface (see diagram later). Medium energy ion scattering results revealed that after Ni silicidation, Sb segregates near the interface with $\mathrm{SiO}_{2}$. In addition, it was observed by XPS that $\mathrm{Sb}$ and $\mathrm{Al}$ appear in metallic and fully oxidized states, respectively. However, Al profiling near Si-containing layers is a challenging task for any ion scattering technique due to the small mass difference between $\mathrm{Al}$ and $\mathrm{Si}$ atoms. Thus, details on the aluminum depth distribution cannot be determined by MEIS and therefore the mobility of this dopant and its eventual interface segregation during metal silicidation still need clarification. This letter reports on the quantification and profiling of implanted $\mathrm{Al}$ atoms after thermally induced metal

${ }^{a)}$ Electronic mail: pezzi@if.ufrgs.br silicidation using a sensitive, isotope selective, and high depth resolution profiling technique, namely resonant nuclear reaction profiling. ${ }^{5,6}$

In order to quantify implanted $\mathrm{Al}$ as well as to investigate its mobility and eventual interfacial segregation after $\mathrm{Ni}$ silicidation, two very narrow and isolated resonances in the cross-section curve of the ${ }^{27} \mathrm{Al}(p, \gamma){ }^{28} \mathrm{Si}$ nuclear reaction were used, namely the ones at $404.9 \mathrm{keV}$ (Refs. 7 and 8) and $992 \mathrm{keV} .^{9,10}$ The former is used here for high depth resolution profiling, owing to the relatively large stopping power of protons at this intermediate energy as well as to the extremely low width of the nuclear resonance $(\Gamma<50 \mathrm{eV})$. The latter presents a much larger cross section, being thus ideal for $\mathrm{Al}$ quantification, although leading to much lower depth resolution due to the lower stopping power of protons in this higher energy range.

Samples of the present work were prepared in an inverted $\mathrm{Si} / \mathrm{Ni}$ configuration, as shown later. The thicknesses of the $\mathrm{Ni}$ and $\mathrm{Si}$ layers where conveniently chosen in order to ensure total $\mathrm{Ni}$ silicidation. The top silicon layer was then implanted with $5 \times 10^{15} \mathrm{Al}$ atoms $/ \mathrm{cm}^{2}$ to a projected range of $20 \mathrm{~nm}$. The structures were loaded into the rapid thermal annealing unit after cleaning and HF etching, then annealed at temperatures ranging from 160 to $700{ }^{\circ} \mathrm{C}$ for $60 \mathrm{~s}$ at a pressure of $6 \times 10^{-7}$ mbar, forming the NiSi structure with an overlying $\mathrm{SiO}_{2}$ cap. Air exposure and residual oxygen during annealing were responsible for surface $\mathrm{Si}$ oxidation, forming a $\mathrm{SiO}_{2}$ layer of thickness around $1 \mathrm{~nm}$.

Figure 1 shows the excitation curves from the as implanted and annealed samples using the ${ }^{27} \mathrm{Al}(p, \gamma){ }^{28} \mathrm{Si}$ nuclear reaction near the resonance at $992 \mathrm{keV}$. Figure 2 shows the corresponding $\mathrm{Al}$ profiles and a sketch of the inverted $\mathrm{Si} / \mathrm{Ni}$ sample configuration in the inset. These profiles were determined with a typical depth resolution of $10 \mathrm{~nm}$ using numerical simulations based on stochastic modeling of ion-energy loss. ${ }^{5,11}$ The $\mathrm{Al}$ profile corresponding to the nonannealed sample perfectly matches the one obtained from a stopping and range of ions in matter ${ }^{12}$ simulation of $\mathrm{Al} \mathrm{im}-$ 


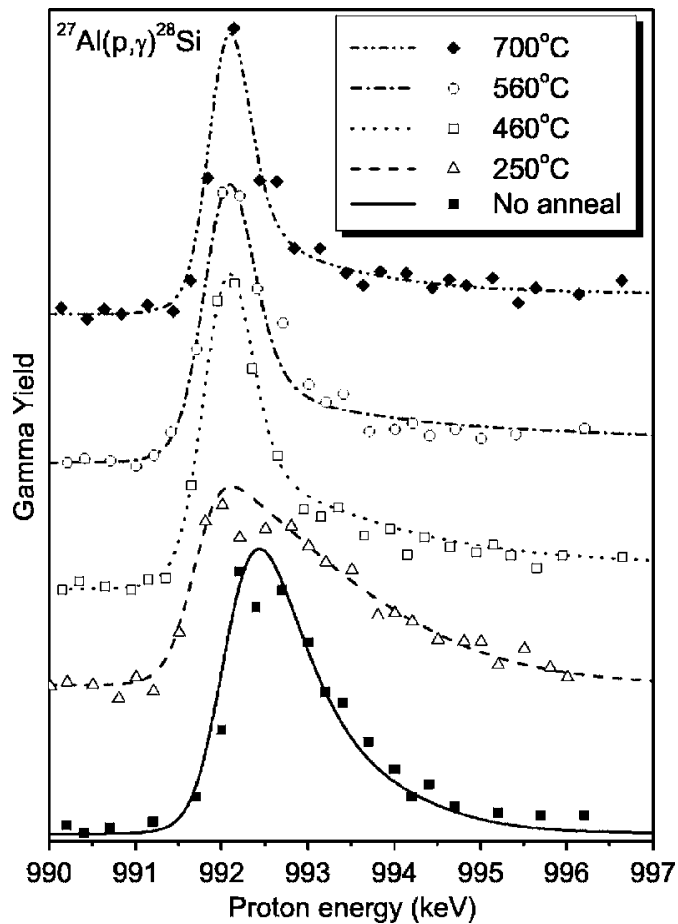

FIG. 1. Experimental (symbols) and numerically simulated (lines) excitation curves of the ${ }^{27} \mathrm{Al}(p, \gamma){ }^{28} \mathrm{Si}$ nuclear reaction near the resonance at $992 \mathrm{keV}$, corresponding to samples implanted with $5 \times 10^{15} \mathrm{Al} / \mathrm{cm}^{2}$ before and after vacuum annealing at different temperatures.

planted into a Si matrix. Furthermore, one can observe that implanted $\mathrm{Al}$ diffuses and segregates near the sample surface during metal silicidation annealing.

The relatively poor depth resolution $(\sim 10 \mathrm{~nm})$ achievable using the nuclear resonance at $992 \mathrm{keV}$ prevents one from observing interesting details about $\mathrm{Al}$ depth distribution near $\mathrm{SiO}_{2} / \mathrm{NiSi}$ interface. Much better depth resolution $(\sim 1 \mathrm{~nm})$ can be achieved when using the resonance at $404.9 \mathrm{keV}$ in the cross-section curve of the same nuclear reaction. Figure 3 shows the excitation curve around this resonance obtained from the sample annealed at $460{ }^{\circ} \mathrm{C}$ for $60 \mathrm{~s}$. The corresponding $\mathrm{Al}$ profile is shown in the inset. It is noteworthy that due to the large stopping power of protons at intermediate energies, the observed peak near the resonance energy corresponds solely to $\mathrm{Al}$ located very close to the

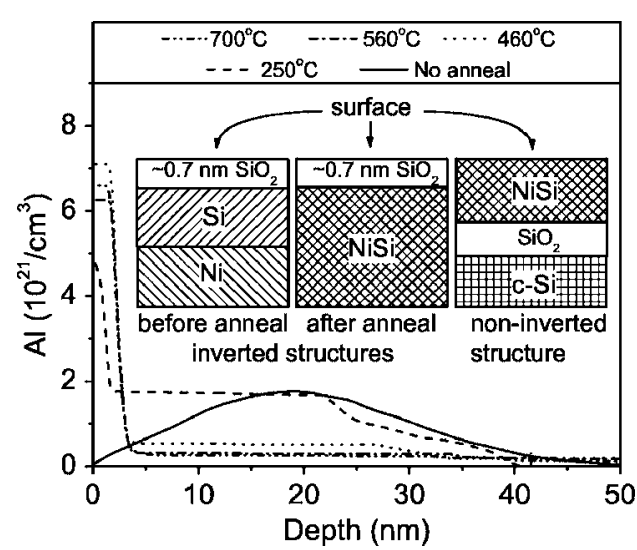

FIG. 2. Al depth profiles as determined by numerical simulation of the curves shown in Fig. 1. Sketches of the inverted device structures before and after metal silicidation as well as a noninverted FUSI structure are shown in the inset. The line styles are the same as in Fig. 1.

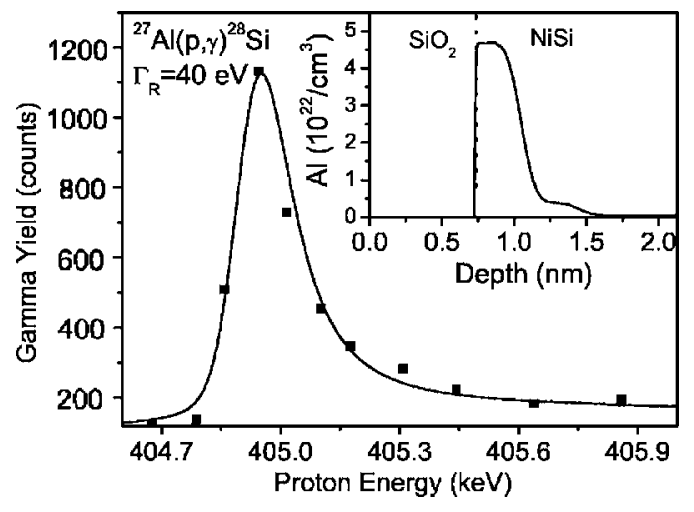

FIG. 3. High resolution $(\sim 1 \mathrm{~nm})$ excitation curve of the ${ }^{27} \mathrm{Al}(p, \gamma){ }^{28} \mathrm{Si}$ nuclear reaction near the resonance at $404.9 \mathrm{keV}$ from the sample annealed at $460{ }^{\circ} \mathrm{C}$ for $60 \mathrm{~s}$. The solid circles represent the experimental points and the solid line represents the simulated excitation curve, assuming the $\mathrm{Al}$ profile shown in the inset.

$\mathrm{SiO}_{2} / \mathrm{NiSi}$ interface. This is in contrast with the curves shown in Fig. 1, which reveal a constant concentration tail into the silicide layer, faraway from the maximum depth inspected in Fig. 3 (notice the different horizontal scales in the Al profiles in Figs. 1 and 3). The Al profile shows no evidence of $\mathrm{Al}$ penetration into the surface silicon oxide layer. Moreover, it reveals that $\mathrm{Al}$ atoms are segregated in a very narrow layer $(\sim 0.5 \mathrm{~nm})$ under the $\mathrm{SiO}_{2}$ cap, reproducing the behavior of $\mathrm{Sb}$ as a NiSi dopant. ${ }^{4}$

Figure 4 shows the total (squares) and near-surface segregated (circles) $\mathrm{Al}$ coverages in the $\mathrm{NiSi}$ samples versus annealing temperature, as determined from the excitation curves and corresponding $\mathrm{Al}$ depth profiles, calibrated against a 2-nm-thick $\mathrm{Al}_{2} \mathrm{O}_{3}$ film on $\mathrm{Si}$. Within experimental errors, no loss of $\mathrm{Al}$ is observed for temperatures up to $700{ }^{\circ} \mathrm{C}$. Moreover, it is clear from Figs. 1 and 4 that aluminum segregation starts to occur at temperatures as low as $160{ }^{\circ} \mathrm{C}$, presenting a saturation point near $380{ }^{\circ} \mathrm{C}$. This is in contrast to what was reported for $\mathrm{Sb}$ as a dopant in $\mathrm{NiSi}$, in which case a metallic Sb segregation peak near $400{ }^{\circ} \mathrm{C}$, followed by substantial Sb loss at higher annealing temperatures were observed. ${ }^{4}$ This contrasting behavior of $\mathrm{Al}$ as compared to $\mathrm{Sb}$ is another indication that the $\mathrm{Al}$ atoms that reach the $\mathrm{NiSi} / \mathrm{SiO}_{2}$ interface oxidize, scavenging $\mathrm{O}$ from either the $\mathrm{SiO}_{2}$ layer, residual gas, or even from bulk poly-

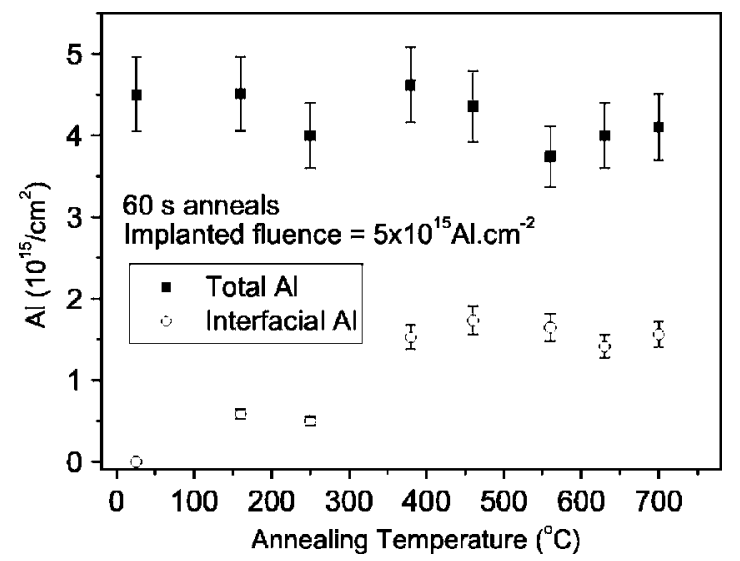

FIG. 4. (Squares): total $\mathrm{Al}$ areal densities as obtained from the areas under the excitation curves of the ${ }^{27} \mathrm{Al}(p, \gamma){ }^{28} \mathrm{Si}$ nuclear reaction. (Circles): $\mathrm{Al}$ segregated near the interface with the silicon oxide as obtained from integration of the near-surface peaks shown in Fig. 2. 
$\mathrm{Si} / \mathrm{Ni}$ to form $\mathrm{Al}_{2} \mathrm{O}_{3}$. Alumina on its turn, is known to be thermodynamically stable in contact with $\mathrm{SiO}_{2}$, while $\mathrm{Sb}$ presents a weak metallic bond to the $\mathrm{NiSi}$, easily desorbing from the interface. Moreover, the reported threshold shifts for $\mathrm{Al}$ in NiSi are similar in sign to those reported for $\mathrm{Al}_{2} \mathrm{O}_{3}$ films on $\mathrm{Si}^{13}$ Thus, the threshold voltage shifts are apparently caused by the thin $\mathrm{Al}_{2} \mathrm{O}_{3}$ interfacial layer, owing to fixed charge in this layer. Other possible causes of threshold voltage shifts are diffusion during dopant activation anneals or the extended implanted $\mathrm{Al}$ range caused by straggling. However, this subject is still deserving further clarification.

In summary, resonant nuclear reaction profiling has been used in the investigation of $\mathrm{Al}$ mobility during $\mathrm{Ni}$ silicidation. $\mathrm{Al}$ atoms are seen to segregate near the $\mathrm{SiO}_{2} / \mathrm{NiSi}$ interface forming aluminum oxide within a narrow layer $(\sim 0.5 \mathrm{~nm})$ close to the interface with the $\mathrm{SiO}_{2}$ cap. Moreover, the $\mathrm{Al}_{2} \mathrm{O}_{3}$ layer is thermally stable, remaining intact even for $\mathrm{Ni}$ silicidation carried at temperatures as high as $700{ }^{\circ} \mathrm{C}$

Financial support from the Brazilian agencies CAPES, FAPERGS, and CNPq is acknowledged.

${ }^{1}$ J. Kedzierski, E. Nowak, T. Kanarsky, Y. Zhang, D. Boyd, R. Carruthers, C. Cabral, R. Amos, C. Lavoie, R. Roy, J. Newbury, E. Sullivan, J. Benedict, P. Saunders, K. Wong, D. Canaperi, M. Krishnan, K.-L. Lee, B. A.
Rainey, D. Fried, P. Cottrell, H.-S. P. Wong, M. Ieong, and W. Haensch, Tech. Dig. - Int. Electron Devices Meet. 2002, 247.

${ }^{2}$ J. Kedzierski, D. Boyd, P. Ronsheim, S. Zafar, J. Newbury, J. Ott, C. Cabral, M. Ieong, and W. Haensch, Tech. Dig. - Int. Electron Devices Meet. 2003, 13.3.1.

${ }^{3}$ Z. Krivocapic, W. Maszara, K. Achutan, P. King, J. Gray, M. Sidorow, E. Zhao, E. Zhang, A. Chan, A. Marathe, and M.-R. Lin, Tech. Dig. - Int. Electron Devices Meet. 2002, 271.

${ }^{4}$ M. Copel, R. P. Pezzi, and C. Cabral, Jr., Appl. Phys. Lett. 86, 251904 (2005).

${ }^{5}$ B. Maurel, G. Amsel, and J. P. Nadai, Nucl. Instrum. Methods Phys. Res. 197, 1 (1982).

${ }^{6}$ I. J. R. Baumvol, Surf. Sci. Rep. 36, 1 (1999).

${ }^{7}$ S. E. Hunt and W. M. Jones, Phys. Rev. 89, 1283 (1953).

${ }^{8}$ E. P. Gusev, M. Copel, E. Cartier, I. J. R. Baumvol, C. Krug, and M. A. Gribelyuk, Appl. Phys. Lett. 76, 176 (2000).

${ }^{9}$ G. Amsel, J. P. Nadai, E. D'Artemare, D. David, and J. Girard, and E. Moulin, Nucl. Instrum. Methods Phys. Res. 92, 481 (1971).

${ }^{10}$ M. M. Frank, Y. J. Chabal, M. L. Green, A. Delabie, B. Brijs, G. D. Wilk, M. Y. Ho, E. B. O. da Rosa, I. J. R. Baumvol, and F. C. Stedile, Appl. Phys. Lett. 83, 740 (2003).

${ }^{11}$ I. Vickridge and G. Amsel, Nucl. Instrum. Methods Phys. Res. B 45, 6 (1990).

${ }^{12}$ J. Ziegler, SRIM - The Stopping and Range of Ions in Matter (2005), URL http://www.srim.org/

${ }^{13}$ D. A. Buchanan, E. P. Gusev, E. Cartier, H. Okorn-Schmidt, K. Rim, M. A. Gribelyuk, A. Macuta, A. Ajmera, M. Copel, S. Guha, N. Bojarczuk, A. Callegari, C. D’Emic, P. Kozlowski, K. Chan, R. J. Fleming, P. C. Jamison, J. Brown, and RK. Arndt, Tech. Dig. - Int. Electron Devices Meet. 2000, 223. 